\title{
A Probabilistic Tsunami Hazard Assessment for Western Australia
}

\author{
David Burbidge, ${ }^{1}$ Phil R. Cummins, ${ }^{1}$ Richard Mleczko, ${ }^{1}$ and Hong Kie Thio ${ }^{2}$
}

\begin{abstract}
The occurrence of the Indian Ocean Tsunami on 26 December, 2004 has raised concern about the difficulty in determining appropriate tsunami mitigation measures in Australia, due to the lack of information on the tsunami threat. A first step in the development of such measures is a tsunami hazard assessment, which gives an indication of which areas of coastline are most likely to experience tsunamis, and how likely such events are. Here we present the results of a probabilistic tsunami hazard assessment for Western Australia (WA). Compared to other parts of Australia, the WA coastline experiences a relatively high frequency of tsunami occurrence. This hazard is due to earthquakes along the Sunda Arc, south of Indonesia. Our work shows that large earthquakes offshore of Java and Sumba are likely to be a greater threat to WA than those offshore of Sumatra or elsewhere in Indonesia. A magnitude 9 earthquake offshore of the Indonesian islands of Java or Sumba has the potential to significantly impact a large part of the West Australian coastline. The level of hazard varies along the coast, but is highest along the coast from Carnarvon to Dampier. Tsunamis generated by other sources (e.g., large intraplate events, volcanoes, landslides and asteroids) were not considered in this study.
\end{abstract}

Key words: Tsunami, probabilistic hazard assessment, Western Australia, earthquake recurrence, Sunda Arc, subduction zone.

\section{Introduction}

Western Australia appears to experience larger tsunamis with a higher frequency of occurrence than other parts of Australia, primarily due to its proximity to the zone of tectonic activity known as the Sunda Arc, which skirts the southern edge of the Indonesian archipelago. In addition to the Indian Ocean Tsunami of 2004, four tsunami events have affected the coast of Western Australia with runup (maximum inundation height above sea level reached by the tsunami) of 2 meters or more (Fig. 1), with the maximum recorded runup of 9 meters originating from the July 2006 Java earthquake. Although tsunamis have as yet caused no confirmed fatalities in Australia, dozens of bathers on some WA beaches were dragged out to sea (and subsequently rescued by boat) during the 2004 Indian Ocean Tsunami, and campers at Steep point (the purple bar in Fig. 1) were lucky to escape with their lives following the tsunami caused by the 2006 Java earthquake (The Western Australian, 19 July, 2006).

\footnotetext{
${ }^{1}$ Geoscience Australia, GPO Box 378, Canberra, ACT 2601, Australia. E-mail: phil.cummins@ga.gov.au

2 URS Corporation, 566 El Dorado Street, Pasadena, CA, U.S.A.
} 
Assessing just how often and where significant tsunami runup might occur, however, is a difficult problem that would require either an extensive catalogue of historical tsunami inundation events, or sophisticated numerical modelling of the shoaling and inundation that occurs when a tsunami reaches the shoreline. The former does not exist for Western Australia, since there is little or no historical record prior to the 1800 s. To the best of the authors' knowledge there has not previously been a probabilistic tsunami hazard assessment specifically for WA, although some preliminary assessments based on limited historic data or a restricted set of numerical models have been completed (RYNN and Davidson, 1999; Burbidge and Cummins, 2007). Here we present the first probabilistic tsunami hazard assessment for WA expressed in terms of an offshore tsunami amplitude which has a given probability of being exceeded per year. Offshore is defined here to be a water depth of $50 \mathrm{~m}$ or greater. Because the modelling of tsunami at this depth or greater is considerably simpler and is less sensitive to shallow bathymetry, thousands of potential sources of tsunami can be simulated, and the results combined into an aggregate 'offshore tsunami hazard map' that should provide some indication of which broad areas of the Western Australian coast are susceptible to tsunami impacts. These areas can then be taken as the focus of subsequent work using more detailed inundation modelling.

The tsunami hazard assessment described here was commissioned by the Fire and Emergency Services Authority of Western Australia (FESA) to cover the coastline of Western Australia. The coastline at which tsunami hazard has been assessed is therefore that of continental Australia west of $130^{\circ} \mathrm{E}$ longitude. Although results for other coastlines may appear in some figures, the hazard assessment presented here may not be valid for these coastlines (e.g., local tsunami may not have been adequately considered for Christmas Island or Indonesia). The sources considered to have a significant tsunami impact on the coastline of Western Australia are those in the Indian Ocean - in particular the Sunda Arc, east of $90^{\circ} \mathrm{E}$ longitude and west of $135^{\circ} \mathrm{E}$ longitude (Fig. 2).

The only type of tsunami source considered in this study are subduction zone earthquakes generated along the Sunda Arc, because they are by far the most frequent source of tsunamis that affect the coast of Western Australia. Three quarters of the world's tsunamis are caused by earthquakes (GusiaKov, 2005), and of the 18 historical Indian Ocean-wide tsunami events, only one was not caused by an earthquake (DomINEYHowes et al., 2006). The other sources of tsunamis are:

Volcanic eruptions. The 1883 eruption of Krakatau is the only known major volcanic eruption that has triggered a tsunami which has affected Western Australia. The Krakatau eruption caused a moderate (1-2 m runup) tsunami which was observed all along the WA coast (see Fig. 1). The recurrence time for major eruptions at Krakatau is thought to be 21,000 years (BEAuREGARD, 2001). The potential for other volcanoes in the region generating a tsunami large enough to contribute to the tsunami hazard off WA is unclear.

Asteroid/meteorite impacts. These are a concern for any coastal community, with estimates of return times of 11,000 and 30,000 years for a (respectively) $2 \mathrm{~m}$ and a $5 \mathrm{~m}$ maximum amplitude offshore tsunami impacting Perth (WARD and AsphaUg, 2000). More 


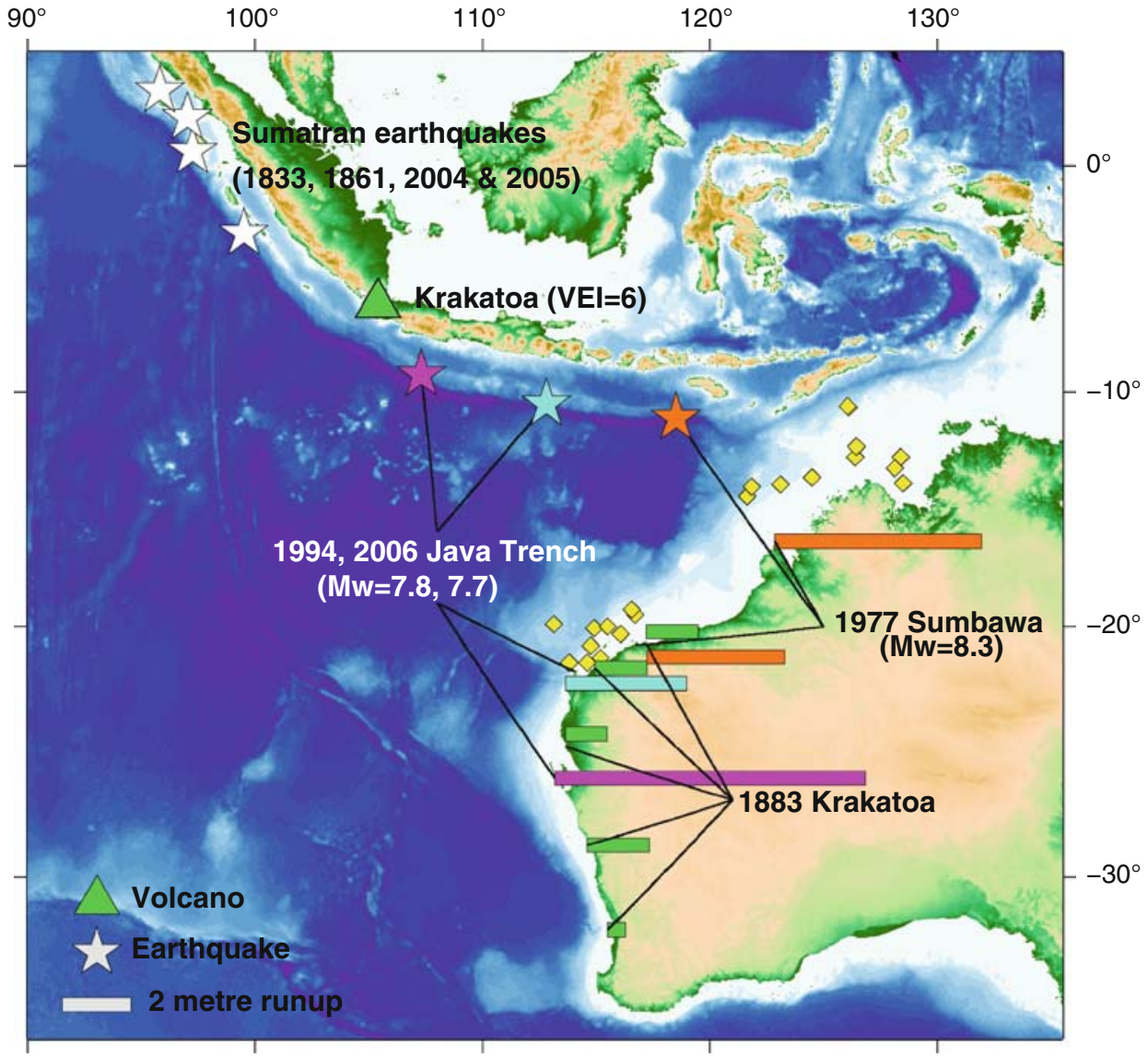

Figure 1

WA Tsunami runup observations and the corresponding tsunamigenic events, with events color-coded to match the runup observations. The basemap shows the bathymetry off the West Australian Coast. $\mathrm{M}_{\mathrm{w}}$ is the moment magnitude, while VEI is the Volcanic Explosivity Index, with 6 for Krakatoa being one of the largest in recorded history. There are no recorded observations in Australia of the tsunami events of 1833 and 1861. The length of the columns increases with the height of the observed runup (the scale of the columns is shown in the bottom left hand corner of the figure)

recent work, however, suggests that both the rates and tsunami impacts of the 200-300 m meteors that dominate this hazard source are grossly overestimated (BLAND and Artemieva, 2003; Melosh, 2003; Korycansky and Lynett, 2005)—although Chesley and WARD (2006) still consider the higher rates and impacts plausible.

Submarine landslides. Submarine landslides near the coast have the potential to produce large, local tsunamis. While there is evidence of large, potentially tsunamigenerating submarine slope failures off Australia's eastern coast (JENKINS and KEENE, 1992), the sparsity of data along the western coast precludes any definitive statement 


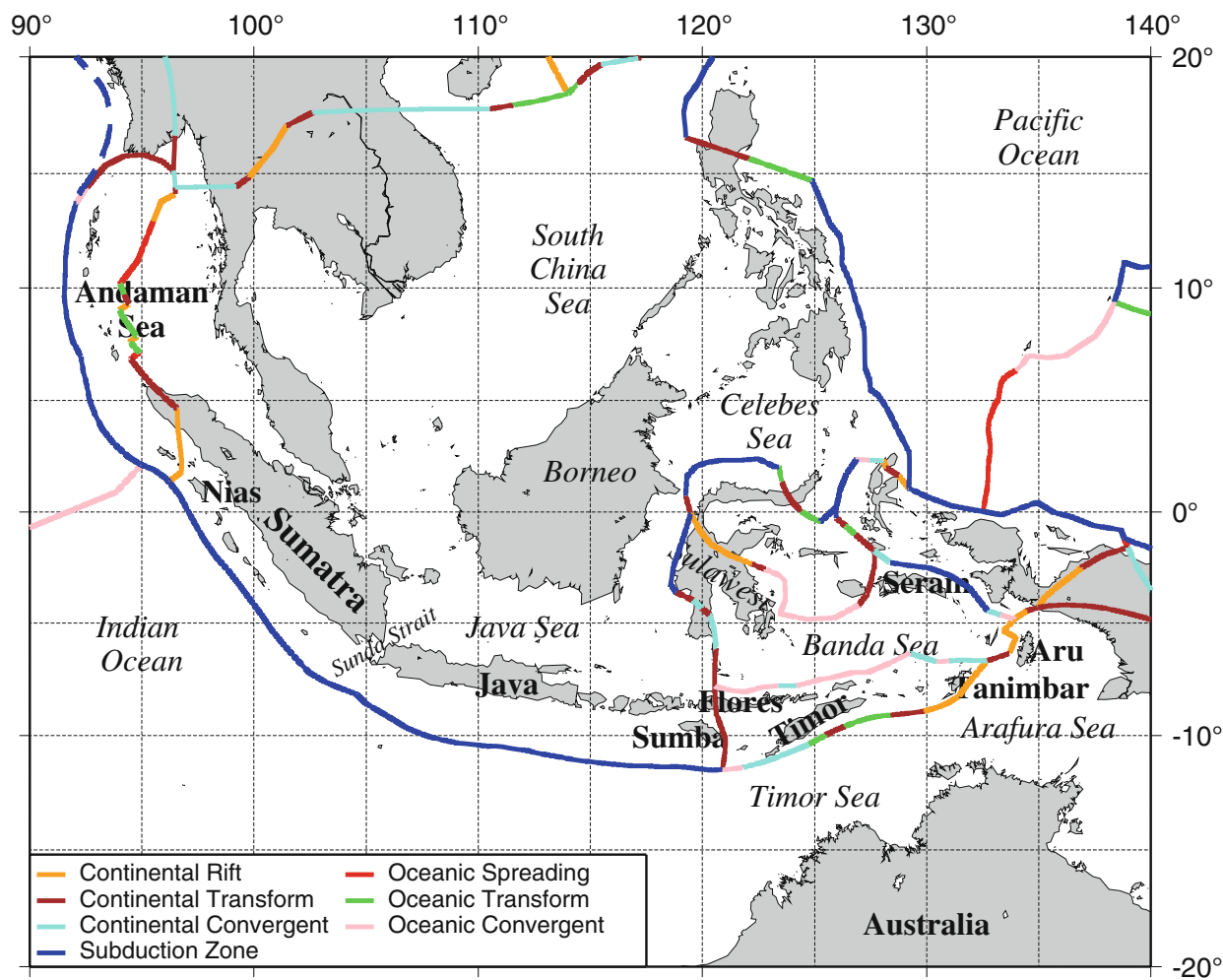

Figure 2

A map of major faults and islands in Indonesia discussed in this study, from BIRD (2003). The northward extension of the Andaman suduction zone (dashed blue line) is from AchARYyA (1998). In the text we refer to plate boundaries by the name of the nearest island (shown in bold type).

about the frequency of submarine slope failures. It is also thought that ocean-wide tsunamis can be produced by massive failure of a volcanic edifice (WARD and DAY, 2001). Although an argument could be made for possible edifice collapse at Heard/McDonald Island, there is no information on the likelihood of such an event occurring.

While there is some evidence that suggests 'megatsunami', possibly generated by the non-earthquake sources described above, may have impacted Western Australia during the past millennium (NOTT and BRYANT, 2003), the evidence is not conclusive. In any case, what we do know of the above non-earthquake sources of tsunamis suggests the recurrence times of such events will be 10,000 years or more.

In this study, we will only quantitatively estimating the tsunami hazard to WA from tsunamis generated by earthquakes along the Sunda Arc. Not including the other nonSunda Arc sources like landslides has the effect of underestimating the total tsunami hazard. The magnitude of this effect is difficult to estimate because of the large uncertainty in the frequency of many of these non-Sunda Arc zone sources. However, we 
feel that they have the potential to be significant to the hazard for return periods of 10,000 years or longer. Therefore, all hazard maps shown in this paper are for return periods of 2000 years or less, where we feel that tsunamis generated by earthquakes along the Sunda Arc are probably the dominant source of the hazard to WA.

\section{Sunda Arc Earthquake Sources of Tsunami}

In this study we consider the most likely source of tsunamis, earthquakes in the Sunda Arc from the Andaman Islands in the west to Aru in the east (Fig. 2). Although Cummins (2007) has suggested that the earthquake potential for the Sunda Arc extends further northward along the coast of Myanmar, as indicated by the dashed line in Figure 2, tsunamis generated by earthquakes along this extension have not been considered here, because they do not direct significant energy towards WA. We also consider tsunamis from the Flores thrust fault to the north of Timor and the Seram subduction zone. In the following sections we discuss the three main regions of the Sunda Arc subduction zone that could produce tsunamis that could affect WA: Sumatra, Java, and Sumba. Unless otherwise specified, we use the moment magnitude values from the Global CMT project (http://www.globalcmt.org/) in this section. However, we acknowledge that various other researchers may give other estimates which can differ by up to about 0.3 units from the USGS value for specific events by using other methods to calculate the magnitude.

The northern most section (called here the Andaman section) was the site of the $\mathrm{M}_{\mathrm{w}}$ 9.3 (Stein and OKal, 2007) 2004 Andaman earthquake. While this event created the huge Boxing Day tsunami in the northern Indian Ocean, its effects along the WA coast were comparatively small. We consider the Andaman section to be the entire subduction zone from $13^{\circ} \mathrm{N}$ to the Island of Nias. The Sumatran section lies offshore the Island of Sumatra between the triple junction and the Sunda Strait. The Java section is the subduction zone directly to the south of the Island of Java between the Sunda Strait and approximately $113^{\circ} \mathrm{E}$. The Sumba section continues to the east until the subduction zone ends just to the west of the Island of Timor. In the hazard assessments we also include several of the plate boundaries surrounding the Banda Sea; namely: Timor, Tanimbar, Aru, Flores and Seram. Finally, we also discuss the diffuse seismicity between the Indian and Australian plates to the northwest and west of WA.

The purpose of this section is to define the range of sources used in the tsunami hazard map. The discussion of seismicity in the various segments of the Sunda Arc presented here will allow us to establish the combinations of source mechanisms and maximum magnitudes to be used in the logic tree that will serve as the source specification for our hazard map, as described in, e.g., GeIsT and PARsons (2006). Details of this logic tree are presented in Table 1. The dip values for the subduction zones were found by averaging the 0-50 km dip angles of CRUCIANI et al. (2005). The maximum seismogenic depth was found by matching the maximum depth of the sub-faults to observed seismicity along each fault. The other columns in Table 1 are determined in the following sections. 
Table 1

Geometry and physical properties of the fault segments used in the probabilistic tsunami hazard assessment

\begin{tabular}{|c|c|c|c|c|c|}
\hline Segment Name & $\begin{array}{c}\text { Maximum } \\
\text { Magnitude } \\
\left(\mathrm{M}_{\mathrm{w}}\right)\end{array}$ & $\begin{array}{l}\text { Dip } \\
(\operatorname{deg})\end{array}$ & $\begin{array}{c}\text { Maximum } \\
\text { Seismogenic } \\
\text { Depth }(\mathrm{km})\end{array}$ & $\begin{array}{c}\text { Number } \\
\text { p.a. } \geq \\
\mathrm{M}_{\mathrm{w}} 7.0\end{array}$ & $\begin{array}{l}\text { Slip-rate } \\
(\mathrm{mm} / \mathrm{yr})\end{array}$ \\
\hline Andaman Megathrust & $9.3 / 9.5^{1}$ & 14 & 50 & 0.043 & \\
\hline Sumatra Megathrust & $9.3 / 9.5^{1}$ & 15 & 50 & 0.075 & \\
\hline Java Megathrust & $8.5 / 9.0 / 9.3 / 9.5^{2}$ & 16 & 60 & 0.093 & \\
\hline Sumba Megathrust ${ }^{3}$ & $8.5 / 9.0 / 9.3 / 9.5^{2}$ & 14 & 60 & 0.075 & \\
\hline Sumba Normal $^{3}$ & $8.5 / 9.0^{1}$ & 55 & 47 & 0.075 & \\
\hline West Timor Thrust & $7.5 / 8.0^{1}$ & 20 & 17 & & 23.0 \\
\hline East Timor Strike-Slip & $7.5 / 8.0^{1}$ & 73 & 48 & & 17.3 \\
\hline Tamibar Normal & $7.5 / 8.0^{1}$ & 55 & 41 & & 41.0 \\
\hline Wetar-Flores Thrust & $8.0 / 8.5^{1}$ & 20 & 17 & & 34.5 \\
\hline South Aru Strike-Slip & 7.5 & 73 & 48 & & 47.8 \\
\hline Aru Normal & 7.5 & 55 & 41 & & 41.0 \\
\hline South Seram Thrust & 7.5 & 20 & 17 & & 75.7 \\
\hline Seram Megathrust & $8.5 / 9.1^{1}$ & 14 & 30 & 0.031 & \\
\hline West Seram Thrust & 7.5 & 20 & 17 & & 64.9 \\
\hline
\end{tabular}

${ }^{1}$ Two models with these maximum magnitudes are considered for this fault segment, each weighted with a $50 \%$ chance of being correct.

${ }^{2}$ Four models with these maximum magnitudes are considered for this fault segment, each weighted with a $25 \%$ chance of being correct.

3 Two models are considered for the Sumba section of the Sunda Arc, one with only a megathrust and another with both a megathrust and a normal fault; each model is weighted with a $50 \%$ chance of being correct.

\subsection{Sumatra-Andaman}

Historically most of the larger earthquakes offshore Sumatra appear to be shallowdipping thrust fault events on the megathrust, as were the 26 December, $2004 \mathrm{M}_{\mathrm{w}} 9.3$ Andaman earthquake and the $28 \mathrm{March}, 2005 \mathrm{M}_{\mathrm{w}} 8.6$ Nias earthquake, and more recent events in September 2007 (Fig. 3). Great (i.e., larger than magnitude 8.0) thrust earthquakes have also occurred in historic times, prior to the events of 2004 and 2005. Newcomb and McCANN (1987) document the occurrence of three major tsunamigenic earthquakes in 1797, 1833 and 1861. More recent analyses of coral microatolls (Zachariasen et al., 1999, and Natawidjaja et al., 2006) have shown that these events likely ranged from magnitude 8.5 to 8.7 .

Since 1976, a much smaller number of normal faulting events have occurred to the west of the trench on the outer rise (Fig. 3). This type of earthquake appears to occur much less frequently than the megathrust events, and their magnitudes appear to be considerably smaller (rarely greater than $\mathrm{M}_{\mathrm{w}}=7$ ). We therefore discount such events as contributing significantly to the tsunami hazard in Western Australia.

Between the trench and the coast, some strike-slip earthquakes have occurred off Sumatra since 1976. These are thought to be a combination of events on the Mentawai and the Great Sumatran faults. Motion on these faults appears to reflect strain partition of the oblique subduction (Burbidge and Braun, 1998) in the Sumatra section of the Sunda 


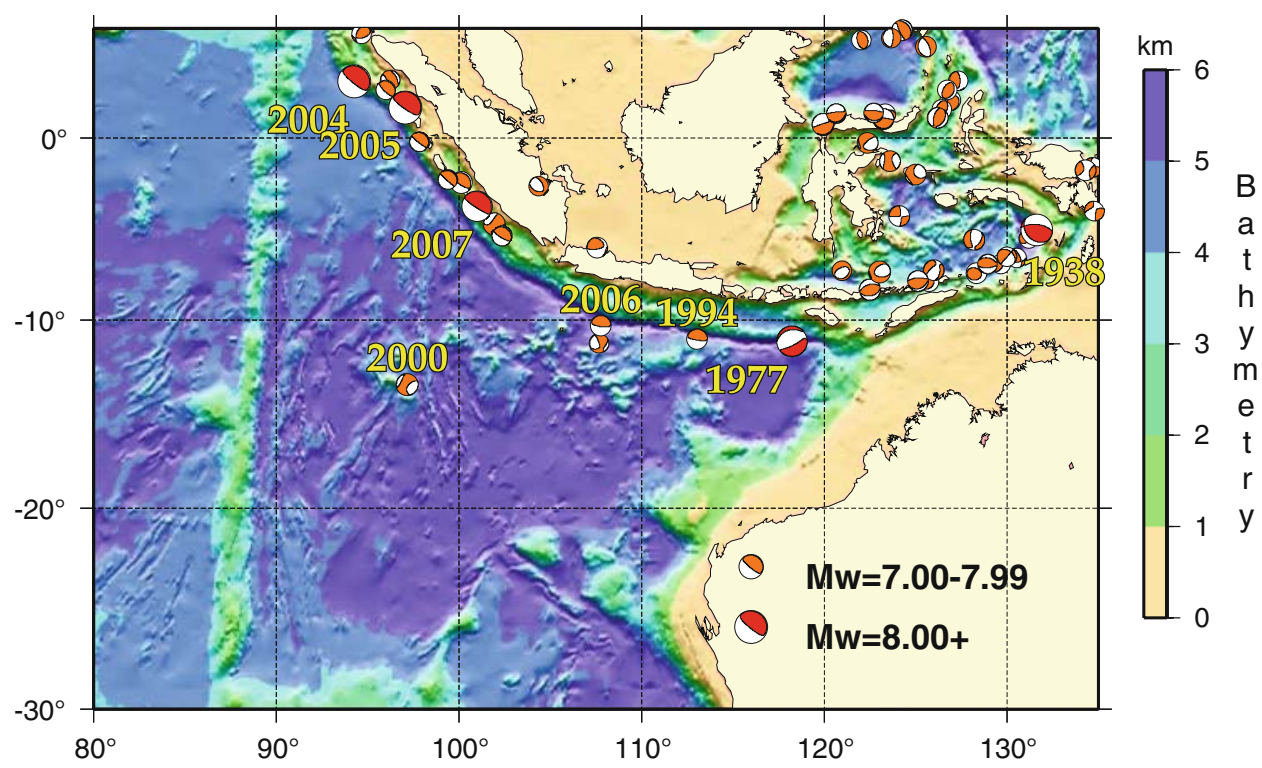

Figure 3

Earthquake focal mechanisms of all the earthquakes in the Global CMT catalogue for the eastern Indian Ocean region since 1976 with $\mathrm{M}_{\mathrm{w}} \geq 7.0$ and depth less than $100 \mathrm{~km}$, as well as the mechanism of OKAL and REYMOND (2003) for the 1938 earthquake. The background shows the bathymetry from the ETOPO2 elevation model. Earthquakes discussed in the text have their years indicated.

Arc. The Great Sumatran fault will not produce any tsunami since it is entirely onshore, so it is not included in the tsunami hazard analysis. The Mentawai fault might generate a tsunami, however because it is a strike-slip fault the amount of uplift is likely to be quite small even for a large earthquake. The Mentawai fault is therefore not included in the probabilistic tsunami hazard analysis because it probably has a small maximum magnitude, a low rate of earthquake occurrence, and the earthquakes that do occur are unlikely to generate large tsunamis.

For the reasons described above, only megathrust earthquakes are considered to contribute to the tsunami hazard in WA for the Sumatra-Andaman section of the Sunda Arc. While the maximum magnitude may be only as large as the largest historical event $\left(\mathrm{M}_{\mathrm{w}}=9.3\right.$, SteIN and OKAL, 2007), the wide megathrust seismogenic zone demonstrated by 2004 and later earthquakes suggests that even larger events may be possible. We therefore consider two branches to the logic tree for this section of the Sunda Arc, one with maximum magnitude of 9.3 and the other with maximum magnitude of 9.5 .

\subsection{Java}

Like the Sumatra section, most of the larger earthquakes offshore Java appear to have been megathrust events. The two largest ones (the $M_{w} 7.81994$ and $M_{w} 7.72006$ Java events, see Fig. 3) are both considerably smaller and occurred closer to the trench than the 
largest Sumatra events in the same period. Both of these events created significant tsunamis along the WA coast (Fig. 1). The 2006 event created the largest confirmed tsunami runup in Australian history at Steep Point (approximately 9 m, purple bar in Fig. 1). These events also created a damaging tsunami in Java and killed hundreds of people. Both of these events are examples of "tsunami earthquakes" which produce larger tsunamis than expected for their earthquake magnitude. Historical reports (Newcomb and McCANN, 1987) indicate that earthquakes in 1875 and 1859 were large, causing more shaking to Java than recent events, but it is hard to estimate exactly how large any earthquakes may have been before the widespread use of seismographs (i.e., anything before the twentieth century). Other historical earthquakes in 1840, 1859 and 1921 affected an extent of coast similar to the more recent earthquakes and shook Java to a similar level.

While there is now no question that earthquakes of magnitude 9 and greater occur in the western Sunda Arc off northern and central Sumatra, the maximum magnitude of earthquakes occurring in the eastern Sunda Arc off Java is unknown. On the one hand, there are arguments that, because the Australian plate being pushed beneath Java is relatively old, the cooler temperature of the interplate contact will lead to a narrow seismogenic zone, hence smaller earthquakes can be expected off Java (RUFF and Kanamori, 1980; Hyndman and Wang, 1993; Oleskevich et al., 1999). This argument is supported by the apparent lack of a wide zone of interplate coupling suggested by geodetic measurements (Bock et al., 2003). Cooler temperatures would also lead to higher densities, lower buoyancy and potentially weaker coupling which may also influence the maximum magnitude and/or rate of seismic moment release. On the other hand, other studies suggest there is little dependence of subduction zone seismicity (rate or maximum magnitude) on plate age (BIRD and KagAN, 2004; NishenKo, 1991; PACHECO et al., 1993), in which case there is no basis for inferring that magnitude 9 earthquakes cannot occur off Java. Wells et al. (2003) have argued that the presence of sedimentary basins between the trench and the coast (the forearc of the subduction zone) correlates with regions of increased megathrust earthquake slip, and since Java and Sumatra both have well developed forearc basins (see, e.g., the seismic reflection profiles of Kopp, 2002), it might be argued that both can host very large earthquakes. Finally, another school of thought suggests that large earthquakes occur when some of the incoming sediment is subducted into a channel between overriding and subducting plates (RuFF and KANAMORI, 1980; RufF 1989). According to LASKE and Masters' (1997) global sediment thickness map, there is a thickness of several kilometers of sediment along the Java trench and even more for southern Sumatra, arguing again for a high maximum magnitude for megathurst earthquakes off Java.

In summary, the age of the plate argues against large earthquakes off Java, but the sediment subduction, rapid convergence and presence of forearc basins argues for it. It should be noted that none of these indications can definitively prove that large earthquakes can or can not occur at a particular subduction zone. In our opinion, the possibility of a large earthquake occurring off Java cannot be ruled out, and we therefore consider a wide range of possible maximum magnitudes for megathrust earthquakes off 
Java: 8.5, similar to the largest historical events, but also 9.0, 9.3 and 9.5 (Table 1) to account for the possibility that much larger events occur but are not reflected in the historical record.

\subsection{Sumba}

To the east of Java there is a major change in the mode of seismicity seen along the Sunda Arc. There have been several major (above magnitude 6.0) normal faulting earthquakes along this section of the Arc. There has also been a host of smaller normal faulting earthquakes right along the trench from Timor to about $113^{\circ} \mathrm{E}$. This is a highly unusual pattern of earthquakes for a subduction zone since they are usually dominated by shallow dipping thrust fault earthquakes rather than normal faulting earthquakes. The largest earthquake in this normal faulting sequence was the $M_{w} 8.3$ Sumba 1977 event (Fig. 3) which caused a significant tsunami along the northwest coast region of Australia to the south (Fig. 1). This event was located to the south of the trench and had an extensive series of aftershocks, most of which also had normal faulting mechanisms (SPENCE, 1986). The 1977 Sumba event was the largest earthquake to have occurred anywhere along the Arc from the Andaman Sea to Timor during the twentieth century.

The extensive normal faulting along this section of the Sunda Arc suggests that a major change in stress occurs between $113^{\circ} \mathrm{E}$ and Timor. This could be due to the relatively old (and thus dense) crust subducting along this section of the Arc. The plate itself may be breaking off along a major normal fault at the trench (SPENCE, 1986). This would have the effect of decoupling the megathrust and is consistent with the small number of earthquakes between the trench and the coast. Although there are some earthquakes with a shallow-dipping focal mechanism beneath the Island of Sumba itself (which is consistent with an active megathrust) these are fairly small and quite rare.

In the hazard model, we have two branches to the logic tree representing two different fault models for this section of the Sunda Arc. One has a normal fault extending from $113.5^{\circ} \mathrm{E}$ to Timor and the other is a shallow-dipping megathrust along the same section of Arc (see Table 1 for details).

\subsection{Banda Sea}

The tectonic history of the eastern Sunda Arc around the Banda Sea has been the subject of many decades of debate. It has been described by some as one of the most complicated tectonic regions on Earth. The Java trench becomes much more shallow south of Timor. From here to Aru it is known as the Timor Trough. There is no evidence of any large (greater than magnitude 6.0) earthquakes to the south of Timor, though some smaller earthquakes have occurred there. They occur on steeply dipping fault planes, are fairly small, and have only occurred south of West Timor. Most of the major earthquakes in this area have occurred to the north of Timor along the Flores and Wetar thrusts (the pink boundary in Fig. 2 running from east to west and lying just to the north of Timor). 
The faults associated with these events are also quite steeply dipping. In between the Flores and Wetar thrusts and the Timor Trough, there is a complicated mixture of earthquake types with no clear dominant mechanism.

To the east, near the Islands of Tanimbar and Aru (Fig. 2), there has been only one major event since 1976 ( $\mathrm{a}_{\mathrm{w}} 6.9$ event in 1988). The events in this region have extensional focal mechanisms. To the north of the Island of Seram we again see shallowdipping thrust earthquakes between the trench and under the island itself, just like those off the southern coasts of Java and Sumatra. This suggests that a southward-dipping active subduction zone exists in this area beneath the island.

An analysis of GPS measurements by Bock et al. (2003) has shown that the convergence rate between the Australian Plate and the islands of the Sunda Arc immediately to its north decreases dramatically east of Sumba. The convergence rate between the Australian Plate and Timor is low, while the islands further to the north (e.g., Sulawesi) are moving much faster towards Australia than Timor is. This suggests that most of the relative convergence is being accommodated to the north of Timor along the Wetar and Flores thrust faults. The GPS data also indicate that the area around Aru and Tanimbar is extensional since it is moving away from the Australian plate.

In our opinion, the most likely explanation for all these observations is that subduction ceased between Timor and Aru when the Australian plate started to collide with Timor (between 2 million and 10 million years ago). Timor consists of lighter continental crust and so will resist subduction. Most of the convergent motion is now being taken up by the Wetar and Flores thrust faults to the north of Timor. The area to the east near Aru appears to be now undergoing rifting, probably also because of the TimorAustralia collision. The Seram area appears to be the only active subduction zone left in the Banda Sea area.

There is no consensus on the nature of the tectonics in the Banda Sea itself. Some argue that the area is convergent (BIRD, 2003); others argue that it is mostly strike-slip (MCCAFFREY, 1988). The latter is more consistent with the recent focal mechanisms; however they are quite complex and subject to multiple interpretations. The largest earthquake in the Banda Sea itself was the 1938 event (Fig. 3). This event has been estimated to have a magnitude of about $\mathrm{M}_{\mathrm{w}} 8.6$ with a thrust mechanism and to be approximately $60 \mathrm{~km}$ deep (OKAL and REYMOND, 2003). It created only a relatively small tsunami for an earthquake of this size, which appears to have caused damage local to the source but did not produce a significant impact in Australia. We believe that any earthquake with a plausible magnitude produced in the central to northern Banda Sea could well produce a local, damaging tsunami in the Banda Sea region. However, any tsunami generated here would be very unlikely to reach Western Australia with a damaging height due to the number of islands between the Banda Sea and Australia.

Due to the great uncertainties and the low likelihood of a hazardous tsunami from the central to north Banda Sea reaching Western Australia, the central Banda Sea itself is not included as a source for the WA tsunami hazard maps. However, the Seram subduction zone, the Timor-Australian plate boundary and the Flores and Wetar thrusts are all 
included as earthquake sources in the probabilistic tsunami hazard map, as indicated in Table 1.

\subsection{Central Indian Ocean}

In June 2000 an $M_{w} 7.9$ event occurred about $150 \mathrm{~km}$ to the southeast of the Cocos (Keeling) Islands in the middle of the Indian Ocean (the isolated focal mechanism in Fig. 3). Analysis of the event indicates that the earthquake started as a strike-slip event but then may have triggered a simultaneous earthquake on another fault (a compound rupture). The second fault has variously been argued to be another strike-slip fault or a thrust fault (AвеRсRомвiE et al., 2003). This earthquake was typical, if large, example of the earthquakes that occur right across the Indian Ocean. Events in this region tend to be a mix of thrust and strike-slip earthquakes. The central Indian Ocean is one of the most seismically active ocean basins, however, its level of activity is still considerably less than the Sunda Arc.

The central Indian Ocean region is currently thought to be a diffuse plate margin separating the Indian and Australian plates (BIRD, 2003). Australia and India are approaching each other by less than $8 \mathrm{~mm} / \mathrm{yr}$ (BIRD, 2003). Unlike other oceanic plate margins this convergence is being accommodated over a region, which is at least 25 degrees in longitude and 15 degrees in latitude. One transect of the region counted 134 active faults over a distance of $2100 \mathrm{~km}$ (Снамот-Rооке et al., 1993). The deformation in this region appears to be accommodated by a complex mix of:

- strike-slip earthquakes along pre-existing transforms formed at the AustralianAntarctic spreading center;

- pre-existing normal faults formed at the spreading center and reactivated as reverse faults; and

- recently formed thrust faults scattered throughout the Indian Ocean.

Since the convergence is spread over so many small faults, the individual slip rate on any fault is probably less than $0.1 \mathrm{~mm} / \mathrm{yr}$. Cumulatively this adds up to the still very small $\sim 8 \mathrm{~mm} / \mathrm{yr}$ of relative convergence between the Indian and Australian plates.

There are far too many faults in this area to consider in a probabilistic tsunami hazard assessment using unit sources (like the one done for this study). One would have to use an areal source, similar to the method used in seismic hazard studies in other intra-plate regions, since there is also no known fault map for the area. The slip rates are probably low, so it is quite likely that the effect on the hazard maps to follow will be very small. However, it is worth keeping in mind that there is a small, but non-zero, chance of a major earthquake (up to at least magnitude 8) occurring anywhere in the Indian Ocean. If they are large enough and located close enough to the coast, they may produce a hazardous tsunami. The return periods for a hazardous tsunamigenic events is likely to be very long for any particular fault. 
Given the high maximum magnitude and the frequent earthquakes, by far the most likely source of tsunamigenic earthquakes that could affect WA is the Sunda Arc subduction zone off Sumatra and Java. However, it should be remembered that it is still possible (albeit very unlikely) to get tsunamigenic events from earthquakes which could be located anywhere in the Indian Ocean. Such events could potentially be included in a future study of tsunami hazard in this region using area-based sources.

\section{Tsunami Hazard Analysis Method}

The goal of hazard assessment is to estimate how likely hazardous events are and how large their effects might be. There are two approaches used for hazard assessment: A scenario or deterministic approach that usually focuses on a maximum credible event and historical experience, and a probabilistic approach that considers a broad range of potential events and their likelihoods. In the case of tsunami, the former is normally used for developing inundation maps and evacuation procedures. Because they contain little or no information about likelihood, however, scenario-based methods are of limited usefulness for broader policy and planning decisions. We therefore consider a probabilistic approach here.

Probabilistic Tsunami Hazard Analysis (PTHA, see, e.g., LiU et al. 2007; GEIST and PARSONS, 2006; WARD and Asphaug, 2000; RiKitAKe and AidA, 1988) was rarely considered until recently-i.e., since the occurrence of the 2004 Indian Ocean Tsunami. PTHA is based on Probabilistic Seismic Hazard Analysis (PSHA, see CoRnell, 1968; McGuire, 1976), which is widely used for insurance, planning and design purposes. PSHA considers the probability that some measure of earthquake ground motion, such as Peak Ground Acceleration, may be exceeded at a location of interest. The implementation of PTHA used here, which was described by THIо et al. (2008), instead considers the probability that a tsunami wave height will be exceeded immediately offshore at a location of interest. Like almost all implementations of PSHA, the theoretical development of PTHA begins with the assumption that events causing a tsunami exceeding some height follow a time-independent Poisson process (see, e.g., page 128 of KRAMER, 1996). Under this assumption, the probability of at least one event occurring in $t$ years that has an offshore tsunami height $h$ greater than $h_{\text {crit }}$ at the location of interest $i$ is:

$$
P^{i}\left(h \geq h_{c r i t}\right)=1-\exp \left(-\phi^{i}\left(h_{\text {crit }}\right) t\right),
$$

where $\phi^{i}\left(h_{c r i t}\right)$ is the annual mean number of events per year that will cause an offshore tsunami height exceeding $h_{c r i t}$ at the location of interest $i . \phi^{i}\left(h_{c r i t}\right)$ is also known as the annual frequency of exceedence. The reciprocal of $\phi^{i}\left(h_{c r i t}\right)$ is known as the 'return period', $\tau^{i}\left(h_{c r i t}\right)=1 / \phi^{i}\left(h_{c r i t}\right) . \phi^{i}\left(h_{c r i t}\right)$ is calculated as the sum over all source zones of the mean number of earthquakes resulting in tsunamis satisfying $h>h_{\text {crit }}$ at the location of interest: 


$$
\phi^{i}\left(h_{\text {crit }}\right)=\sum_{j} N_{j}\left(M \geq M_{c r i t}^{i}\right)
$$

Here $N_{j}\left(M \geq M_{c r i t}^{i}\right)$ is the annual number of earthquakes that occur in source zone $j$, whose magnitude exceeds $M_{c r i t}^{i}$, which is the magnitude of an earthquake that produces a tsunami whose offshore height is $h_{\text {crit }}$ at location $i$. $M_{\text {crit }}^{i}$ here will be determined by numerically modelling tsunamis from various magnitude earthquakes to the coast. The calculation of the functional form of $N_{j}\left(M \geq M_{c r i t}^{i}\right)$ can be based on the historic occurrence of subduction zone earthquakes and/or a relationship between the frequency and magnitude of earthquakes, such as the well-known Gutenburg-Richter law. This is considered in more detail in the next section.

\subsection{Earthquake Frequency}

The simplest way to estimate $N_{j}\left(M \geq M_{c r i t}^{i}\right)$ for earthquakes or tsunamis is from the frequency at which the event has occurred historically. Unfortunately this method is rarely possible for large earthquakes because they happen so infrequently. Before the 2004 Andaman earthquake, no event greater than magnitude 8 was known to have occurred on this fault, so the above method would give a value for $N_{\text {Andaman }}(M \geq 8.0)$ of zero before 2004, a serious underestimate. The last time an event of this size or larger occurred along this part of the subduction zone may have been long before historical records began. Records of seismicity are rarely long enough to estimate earthquake frequency reliably with this empirical method.

Our alternative method for estimating $N_{j}\left(M \geq M_{c r i t}^{i}\right)$ for the Sunda Arc subduction zones segments proceeds as follows:

1. Obtain the most comprehensive global catalogue of earthquakes;

2. Determine which events were generated at subduction zones and remove the rest;

3. Work out for this catalogue how many subduction zone earthquakes per annum occur globally above a given magnitude;

4. Find the best recurrence model which fits this data (e.g., the tapered GutenburgRichter model). This now gives us the global annual frequency of a subduction zone earthquake $N_{G}\left(M \geq M_{x}\right)$ for any magnitude $M_{x}$;

5. Determine the annual frequency of earthquakes above magnitude $M_{x}, N_{j}^{s u b}\left(M \geq M_{x}\right)$, for subduction zone $j$. We use the following equation to do this:

$$
N_{j}^{s u b}\left(M \geq M_{x}\right)=N_{G}\left(M \geq M_{x}\right) \frac{v_{j} L_{j}}{\sum_{i}\left(v_{i} L_{i}\right)},
$$

where $v_{j}$ is the rate of convergence of subduction zone $j$ and $L_{j}$ is its length. The sum in the denominator is taken over all subduction zones in the world large enough to host an earthquake of size $M_{x}$ or greater. The minimum length of the subduction zone required to 
host an event of size $M_{\mathrm{x}}$ is assumed to be $L_{M I N}=M_{x} / \alpha$, where $\alpha=2.0 \times 10^{-2} \mathrm{~km}^{-1}$ from Scholtz (2002). This is quite a conservative minimum and is well below the observed length of historic events above magnitude 7 (the minimum magnitude considered here).

6. Determine the fraction of earthquakes for a given subduction zone that is likely to be on the megathrust (as opposed to some other fault in the subduction zone area like the Great Sumatran fault). When the angle of convergence is low the strain is partitioned between strike-slip faults landward of the outer-arc high and slip on the megathrust. Using the formula of BURBIDGE and BRAUN (1998) we can calculate this angle for each subduction zone (assumed to be about 16 degrees for all the megathrust faults used here). For subduction zones with this obliquity angle or less (partitioned subduction zones) we assume that the annual frequency of an earthquake on the megathrust can be found by:

$$
N_{j}\left(M \geq M_{x}\right)=N_{j}^{s u b}\left(M \geq M_{x}\right) \frac{v_{j}^{c o n}}{\sqrt{\left(v_{j}^{c o n}\right)^{2}+\left(v_{j}^{l a t}\right)^{2}}},
$$

where $v^{c o n}$ is the convergent component perpendicular to the fault and the lateral component is $v^{\text {lat }}$. For all other (non-partitioned) subduction zones $N_{j}\left(M \geq M_{x}\right)$ is assumed to be the same as $N_{j}^{s u b}\left(M \geq M_{x}\right)$.

For steps 1-3 we used the results of BIRD and KaGAN (2004). In this paper they classified earthquakes from the PACHECO and SyKES (1992) catalogue according to the nearest plate margin to the earthquake which is appropriate for that earthquake's focal mechanism. They found that all earthquakes across the globe could be approximated by fitting the tapered Gutenburg-Richter (G-R) relationship. The (non-tapered) G-R relationship states that the number of events with magnitude greater than $M_{x}$ obeys the following relationship:

$$
\log \left[N_{G}\left(M \geq M_{x}\right)\right]=a-b \times M_{x},
$$

where $a$ and $b$ are two constant numbers. They found that $b$ is always close to 1.0 for small earthquakes, despite the different geological settings. However, for large earthquakes the earthquakes became exponentially less common. So they use a tapered G-R relationship to better fit all earthquakes, large or small. The tapered relationship is given by:

$$
N_{G}\left(m \geq m_{x}\right)=\left(\frac{m_{x}}{m_{t}}\right)^{-\beta} \exp \left(\frac{m_{t}-m_{x}}{m_{C}}\right),
$$

where $\beta=2 / 3 b, m$ is the seismic moment, $m_{t}$ is the seismic moment threshold of the catalogue (i.e., the minimum seismic moment that can be reliably determined) and $m_{C}$ is the "corner" seismic moment. The seismic moment is related to the magnitude by (PurCARu and BercKHemer, 1978): 


$$
\log m=1.5 M+9.1 \text {. }
$$

The corner moment $\left(m_{C}\right)$ roughly corresponds to the magnitude at which the G-R relationship began to taper significantly. It is related to the corner magnitude, $M_{C}$, by equation (7).

BIRD and KAGAN (2004) found that the main difference between earthquakes in different geological settings were with their estimates of $a$ and $M_{C}$ for each setting. In the case of subduction zone earthquakes, BIRD and KAGAN (2004) argued that there is no statistically significant justification for subdividing the subduction zone setting into smaller subsets (e.g., subduction zones subducting old crust versus subduction zones subducting new crust). The only effect they noticed was that $a$ increases with the rate of subduction (i.e., how fast the plates were moving closer together). The faster the plates converge the more earthquakes above a certain magnitude occur, hence $a$ is larger. For subduction zones they found that $M_{C}$ was equal to 9.58 . The $90 \%$ confidence interval for this estimate of $M_{C}$ had a lower limit of 9.18 , but had an unbounded upper limit because of the lack of earthquakes with these high magnitudes in the historic record.

From BIRD and KAGAN's (2004) data we can calculate their estimate of $a$ for all subduction zones lumped together (based on the Pacheco catalogue and the maximum probability method described in BIRD and KAGAN (2004)). According to their catalogue, on average 0.5 events greater than $\mathrm{M}_{\mathrm{w}} 8.0$ happen per year somewhere on one of the world's subduction zones. For a Poisson process, this means that the probability of an event greater than $M_{w} 7.5$ ocurring somewhere on the globe per year is about $38 \%$.

However, while this is a good estimate of a global frequency of occurrence, we really need an estimate for the specific subduction zones in this study: Sumatra, Java, Sumba and Seram. To calculate this we use equation (3). This equation was chosen in order to partition $N_{G}\left(M \geq M_{x}\right)$ into different subduction zones according to the area being subducted per annum on the subduction zone $(v L)$. Essentially, this implies that earthquakes of a given magnitude are more likely to occur somewhere on a large, fast-moving subduction zone than on a small and/or slowly converging subduction zone. This is motivated by the observation that earthquakes more frequently occur (have a higher $a$ ) on faster moving subduction zones than small ones because the rate at which the faults are loaded to failure is faster on rapidly converging subduction zones than on slowly moving subduction zones (BIRD and KAGAN, 2004). We believe it is also reasonable to assume that an earthquake is more likely to occur on a longer subduction zone than a smaller one because there are simply more places for an earthquake to happen on a large fault than a small one. The accumulation of tectonic moment on the large fault would be much more rapid, and thus the release of seismic moment can be expected to be more rapid too (KAGAN, 2002). The frequency of a very large earthquake occurring on a subduction zone with length less than $L_{\mathrm{MIN}}$ is zero because the fault is simply too small to host such a large event. Note that splitting up the global seismicity in this way implicitly assumes that the coupling on any given subduction zone is not significantly different from the global average for seismic coupling along megathrusts. 
The length and velocity of every subduction zone in the world was calculated using BIRD's (2003) digitized plate model. Sections of subduction zones within "orogenic zones" are considered to be distinct from those not within orogenic zones. This splits zones such as the Sunda Arc into two (because Sumatra is within an orogenic zone but Java and Sumba are not). Triple junctions also act to segment subduction zones (i.e., they act like a rupture barrier so that earthquakes on one side cannot propagate to the other). Finally, the Sumba and Java sections were also split into two because of the major change in focal mechanisms that occur there.

When the angle between the fault and the direction of convergence is smaller than a critical angle, the strain is partitioned between strike-slip faults landward of the fault and the megathrust. The strike-slip faults take all the lateral motion, while the thrust fault takes up the convergent component of the motion. Using an argument based on work minimization (BURBIDGE and BRAUN, 1998), one can show that the only megathrust fault considered in this study that will be strain partitioned is Sumatra. This is consistent with the fact that only Sumatra has large strike-slip faults between the trench and the coast. Since some of the deformation will be occurring on faults other than the megathrust, this will reduce the frequency of events on the much more tsunamigenic megathrust fault. To represent this we reduce the frequency of all partitioned subduction zones by using equation (4).

Figure 4 shows the return period (the inverse of the annual frequency of exceedence) vs. magnitude for the global subduction zone earthquake catalogue and for six specific subduction zone segments: Java, Sumatra, Sumba, Seram, Nankai (off Japan) and Southern Chile. Our method implies that an event of any given magnitude and year is much more likely on the Java zone, since it is fast and long, and much less likely on Seram, since it is shorter and slower. The Sumba section of the Sunda Arc ends up having much the same frequency of occurrence as the Sumatra section. However, it is important to remember that the Sumba section may or may not be seismically coupled (see discussion in Section 2.3). Since the Sumba section is shorter than the Sumatra section it has a lower maximum magnitude than Sumatra. Events around $\mathrm{M}_{\mathrm{w}} 9.5$ are only possible on long subduction zones like Sumatra, South Chile and Java because of the large area required for a great earthquake of this size. The curves for individual subduction zones flatten at high magnitudes because the tapering of global frequency of earthquakes is almost exactly cancelled by the reduced number of faults big enough to host large earthquakes (the number of large faults decreases exponentially above a certain size, nearly cancelling the exponential taper in equation (6)). This means for the PTHA calculations to follow, we will assume a linear GR relationship up until a given value maximum magnitude. The maximum magnitude chosen depends on fault length and earthquake history along that particular fault.

Nankai and Chile curves are shown in Figure 4 because they have two of the longest catalogues of seismicity anywhere on the globe. The return periods estimated from these catalogues (Scholtz, 2002, for Nankai, and the Servicio Sismologico Universidad de Chile's website for South Chile) are also shown in Figure 4. There have been 11 


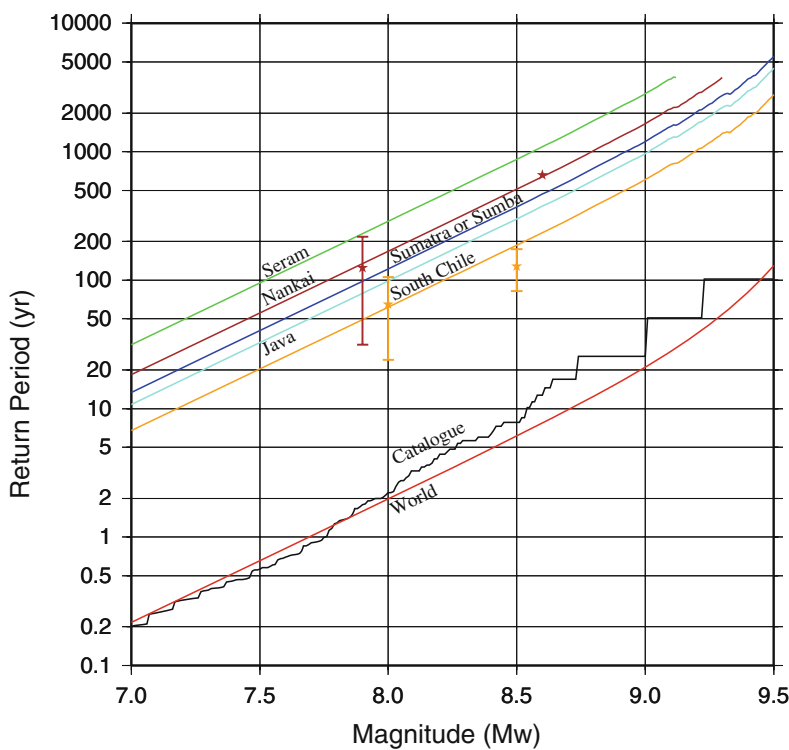

Figure 4

Subduction zone earthquake return period as a function of magnitude. The black line is an empirical model based directly on the maximum probability subset of the Pacheco catalogue (BIRD and KAGAN, 2004). The red line is based on the BIRD and KAGAN's (2004) best fit to these data using the tapered Gutenburg-Richter model. The other lines are the mean return periods for some of the other subduction zones. The zones shown are: Java (cyan), Sumatra (blue), Nankai (brown), Seram (green) and South Chile (orange). The curve for Sumba overlaps Sumatra but has a lower maximum magnitude. The stars with the error bars show the estimated return times from the catalogue by Servicio Sismologico Universidad de Chile and the history of Nankai seismicity described by Scholtz (2002).

events greater than 8.0 on the Nankai subduction zone in the last 1500 years (ScHOLTZ, 2002). Using the historical method this catalogue gives a return period (mean spacing between events of $\mathrm{M} \geq 8.0$ ) of $124 \pm 93$ years. This is statistically indistinguishable from the value calculated with our method (131 years). Similarly the spacing between the two events of magnitude 8.6 or greater (661 years) is very close to our predicted value (640 years).

There is also an extensive seismic catalogue for the southern Chilean subduction zone (the location of the magnitude 9.5 event in 1960). According to the Servicio Sismologico Universidad de Chile's website there have been 7 events greater than 8.0 since 1570 . This gives a return period of $65 \pm 41$ years which compares well with the calculated return period of 61 years. The return period for 8.5 or greater events has been observed to be $128 \pm 46$ years; our model estimates this to 187 years, again quite close (and still within two standard deviations of the observation). Since the Nankai and Chile subduction zones fit this method quite well, this gives us some confidence that the method we are using here to calculate the return periods is reliable. 
The return periods for magnitude 8.0 or greater events for Java, Sumatra, Sumba, Andaman and Seram subduction zones are (respectively) 98 years, 121 years, 122 years, 212 years and 287 years. According to our method, large events occur more frequently on the Java and Sumatra sections of the Sunda Arc than the others studied in this paper. The Sumba megathrust (if coupled) has a similar rate to the Sumatra megathrust. Note that this method does not take into consideration any change in the rate due to the other factors mentioned in the introduction (e.g., sediment, plate age or presence of forearc basins). While these may be linked to the frequency of exceedance, there is currently no way of quantitatively estimating their effect on the earthquake frequency or maximum magnitude. Since this method fits the observations for Nankai and Chile so well, these features may not even be necessary to predict subduction zone earthquake reoccurrence to the accuracy of the historical observations. So for the purposes of this study we will use the values shown in Figure 4 for the subduction zones of interest.

Note that the rates here are for the total seismic release for the subduction zone faults and thus would be comprised of both mainshocks and aftershocks for earthquakes smaller than approximately $M_{w}$. Thus the observed rate of $M_{w} 7$ or smaller events cannot be accurately estimated, even though their return times are less than the instrumental catalogue length, since the number of aftershocks over the last thirty years depends on the number of great $\left(M_{w} 8+\right)$ events over that period. The current rate of $M_{w} 6$ and above for Sumatra, for example, is somewhat higher than a direct extrapolation of the curve shown in Figure 4 would suggest, but this is to be expected since the modern catalogue includes a great earthquake and numerous aftershocks above magnitude 6 . Thus the instrumental rate of $M_{w} 6$ and above over the last few decades may not representative of the long-term rates.

The best value for the maximum magnitude used in the PTHA calculations is highly uncertain, as discussed in Section 2. One can assume that the maximum magnitude is simply a function of length (using SchOLTz's, 2002, formula) or we can assume that it is the largest earthquake known for the area. The length restriction limits the Seram subduction zone to a maximum magnitude of approximately 9.1. The Java, Sumatra and Andaman subduction are all long enough to host events up to (and even beyond) magnitude 9.5 (the size of the 1960 Chilean earthquake).

\section{Hazard Assessment Results}

By combining the information summarized above, we can use the PTHA method to produce a synthetic catalogue of hypothetical earthquakes which includes an estimate of their frequency. The maximum height of the resulting tsunami is then calculated by breaking each fault comprising the tsunamigenic source zones of the Sunda Arc into an array of unit sources. We then numerically model the amount of vertical deformation expected from $1 \mathrm{~m}$ of slip on each unit source using WANG et al.'s (2005) crustal 
Table 2

Crustal properties of the linear elastic crustal layers used to calculate the vertical component of the sea-floor deformation for each unit source

\begin{tabular}{lllc}
\hline $\begin{array}{l}\text { Layer Depth beneath } \\
\text { surface }(\mathrm{km})\end{array}$ & $\begin{array}{c}\text { Compressional } \\
\text { wave speed }(\mathrm{km} / \mathrm{s})\end{array}$ & $\begin{array}{l}\text { Shear wave } \\
\text { speed }(\mathrm{km} / \mathrm{s})\end{array}$ & $\begin{array}{c}\text { Density } \\
\left(\mathrm{kg} / \mathrm{m}^{3}\right)\end{array}$ \\
\hline $0-1$ & 4.5 & 2.4 & 2,700 \\
$1-13$ & 5.6 & 3.3 & 2,700 \\
$13-30$ & 6.2 & 3.7 & 2,900 \\
$30+$ & 7.9 & 4.6 & 3,300 \\
\hline
\end{tabular}

deformation model. The crustal model uses three layers above a vertical half space. The parameters of each layer and the halfspace are shown in Table 2.

We then use the vertical component of the crustal deformation as the initial condition for a staggered grid finite-difference numerical model to propagate each tsunami to the coast. The model solves the linear shallow water wave equations over a 2 minute bathymetry grid. The bathymetry data used is a combination of global bathymetry model, DBDB2 V2 (2004) and a downsampled version of Geoscience Australia's $250 \mathrm{~m}$ bathymetry model for Australia.

The results of these computations are stored in a rapidly accessible library of unit source 'Green's functions' (i.e., the solution to a differential equation for a point source forcing term). Any one of the tsunami used for the calculation of $\phi^{i}\left(h_{c r i t}\right)$ can then be simulated by appropriately scaling and summing the results for the combination of unit sources that most closely represents the actual earthquake to be simulated. (Note that this type of source decomposition is mathematically valid only for the linear shallow water simulations used in this study-e.g., they would not be valid for non-linear inundation simulations). For this study, over 5000 earthquakes were simulated in this manner using about 500 unit sources, each corresponding to a $50 \mathrm{~km} \times 50 \mathrm{~km}$ subfault. The subfaults were spaced evenly along the strike and down the dip of each fault.

At the end of this process, we now have a maximum tsunami amplitude estimate for each hypothetical earthquake. Since we also have an estimate of the frequency of the earthquake, we can then calculate the wave height which has the required probability of being exceeded (i.e., the tsunami hazard) for points along the WA coast. Below we consider three ways of visualising the hazard: hazard curves, hazard maps, and deaggregated hazard.

\subsection{Hazard Curves and Uncertainty}

While the goal of any hazard assessment is to give a best estimate of likelihood and impact, it is also important to address the issue of how uncertain these estimates may be. All of the parameters summarized in Table 1 are known with only limited precision, so they all contribute to the uncertainty in this hazard assessment. Other parameters, such as 


\section{Figure 5}

Some hazard curves for points off the coast of WA and Java. All the points are in water close to $50 \mathrm{~m}$ deep. The $x$ axis shows the return period, and the $y$ axis shows the wave height exceedances. The blue, cyan, orange and red curves are four models with different estimates of the maximum magnitude earthquake possible on the Java subduction zone (8.5, 9.0, 9.3 and 9.5, respectively). The red curve is usually the "worst case" scenario since it assumes the largest maximum magnitude. The green and black curves are two different models of the Sumba subduction zone. The black curve assumes that the megathrust fault is completely uncoupled and the green one assumes that it is completely coupled to the subducting plate. The thick purple line is our preferred model which is a weighted mean of all the other curves on these figures.

the elasticity of the crust which controls the sea-floor deformation and therefore the size of the initial wave, also contributes to the uncertainty in the final hazard assessment. However, at least for the longer return periods, we believe that two of the largest sources of uncertainty are our poor knowledge of (a) the maximum magnitude of the largest earthquake along the Java section of the trench $\left(\mathrm{M}_{\max }^{\mathrm{J}}\right)$ and (b) the presence or absence of a normal fault along the Sumba section of the Sunda Arc. Figure 5 shows some hazard curves (i.e., exceedance height of offshore tsunami as a function of return period) for selected locations off the coast of WA and one for a location on the south coast of Java (near the town of Cilacap). The preferred model is the purple curve in Figure 5. For the preferred model we have given an equal weighting to the $\mathrm{M}_{\max }^{\mathrm{J}}=8.5$ (blue), 9.0 (cyan), 9.3 (orange) and 9.5 (red) models in the logic tree (i.e., they each have a $25 \%$ chance of being correct) and the two Sumba models (i.e., both the normal only (black) and megathrust only (green) fault models have a 50\% chance of being correct). Over 5,100 events were included in the preferred (evenly weighted) model, one for each branch of the logic tree. For most locations the preferred model (the purple curve) has a similar hazard curve to the $M_{\max }^{\mathrm{J}}=9.0$ model (the cyan curve). Note that this is the "deepwater" wave height at depths of around $50 \mathrm{~m}$. At depths shallower than this the wave shoals significantly and runups could be several times the values shown here. The exact runup amplification factor will vary significantly along the coast depending on the details of the local bathymetry.

The spread in the hazard estimates for the longer return periods shown in Figure 5 gives some idea of the effect of model uncertainty on our hazard estimates. For small return periods the different models do not tend to have much effect on the hazard. At the longer return periods the uncertainty in $\mathrm{M}_{\max }^{\mathrm{J}}$ has a considerable impact on the hazard for locations along the Java coast (like Cilacap) and locations south of about Exmouth (e.g., offshore Fremantle). For locations along the northwest shelf, the model chosen for the Sumba section can also have a significant impact on the wave heights. If only the normal fault is active (the black curve), the hazard is much lower than if only the megathrust is active (the green curve) or if they have a 50/50 chance of being active (the cyan curve). Constraining the wave heights at the longer return periods is always going to be quite uncertain because our historic catalogues do not go back far enough to constrain the maximum magnitudes or (in the case of Sumba) even the type of earthquake we can expect at the zone. 
Cilacap

Mean Return Period (years)

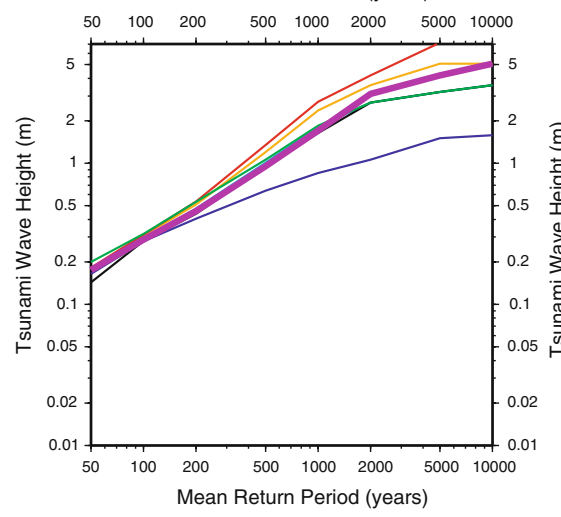

Broome

Mean Return Period (years)

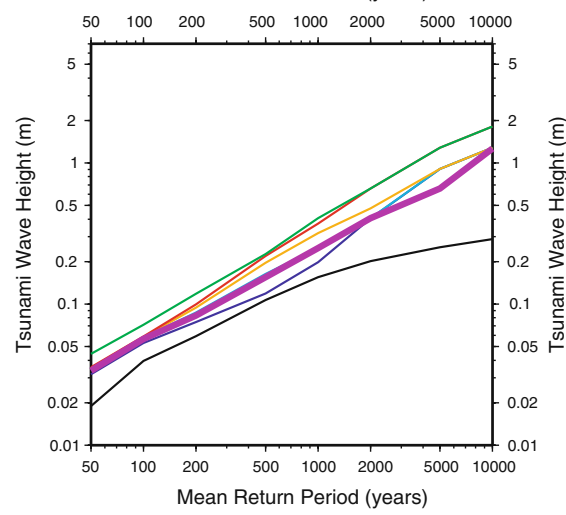

Geraldton

Mean Return Period (years)

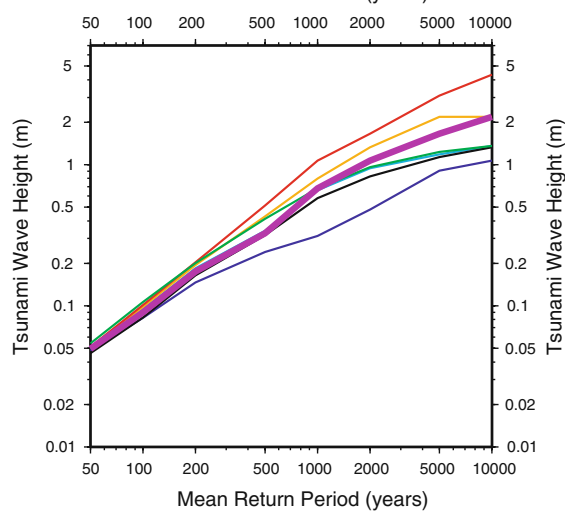

Albany

Mean Return Period (years)

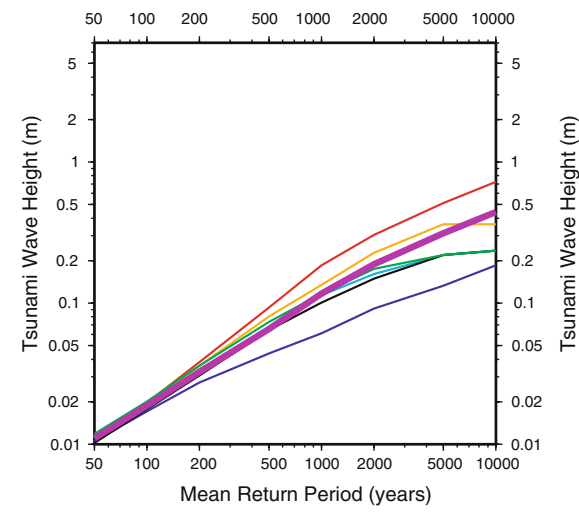

Exmouth

Mean Return Period (years)

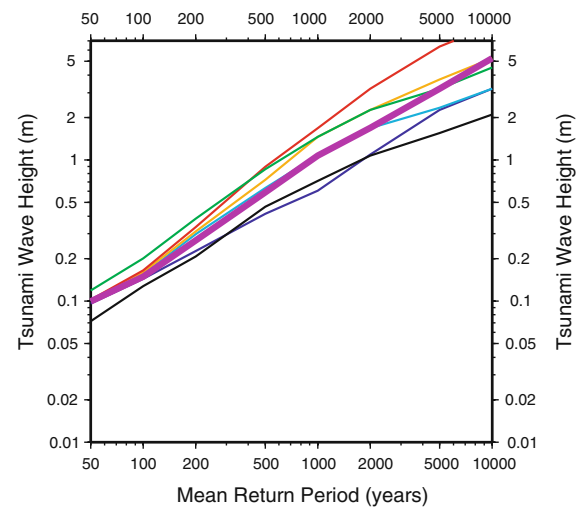

Fremantle

Mean Return Period (years)

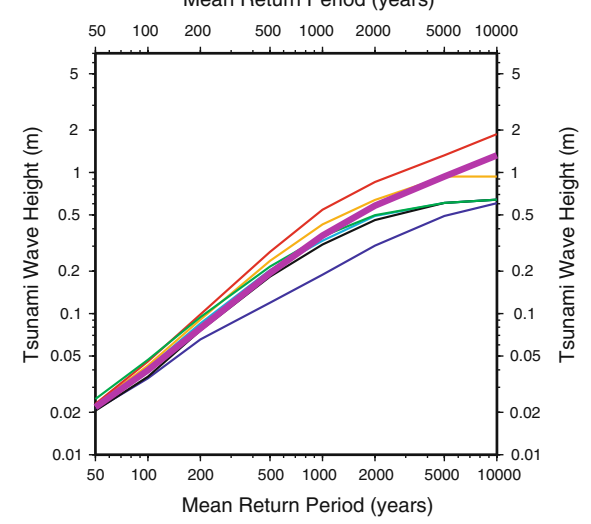


There are other sources of uncertainty which we were not able to include since we needed to keep the number of branches of the logic tree to reasonable values $(5,100$ branches in this case). For example there is the uncertainty due to errors in the bathymetry, uncertain crustal properties (e.g., elastic parameters) and fault geometry (e.g., dip, rupture area, rupture width, etc). We also assume uniform slip and use the linear shallow water wave equation to solve the propagation of the tsunami. Non-uniform slip is likely to be more important closer to the source (GeIST, 2002), but can also be important in the far field, particularly if islands are in the rupture zone of the earthquake. Nonlinear effects on the wave propagation (such as dispersion) may also become important (HoriLlo et al., 2006). All these uncertainties, could in principle, be included in a probabilistic hazard analysis by adding more branches to the appropriate logic trees. However, in practice this is limited by the computational resources available to do the PTHA. Future PTHA are likely to cover a wider range of possibilities than can be considered here, but Figure 5 should give at least some indication of the likely effect of some of the uncertainty for at least $\mathrm{M}_{\max }$.

\subsection{Hazard Maps}

Figure 6 shows the maximum wave heights for different return periods for points interpolated to the $50 \mathrm{~m}$ contour off the coast of WA for the preferred model (the purple curve in Figure 5).

The maximum wave heights increase very rapidly with return period. For return periods approaching 2000 years it is very likely that at least one major earthquake (above magnitude 8.5) will occur somewhere along the Java-Sumba sections of the Sunda Arc and create a significant wave. These large waves could inundate a large section of the coast within a few hours, greatly complicating emergency response.

For any given return period, the hazard is largest for WA in the Shark Bay to Exmouth region. The continental shelf tends to reflect energy away from the northwest coast so its hazard tends to be smaller to the northeast of Exmouth. The hazard south of Shark Bay is much lower since it is not in the direct path of any tsunami generated along the Sunda Arc. The hazard along the south coast of WA is very small from tsunami generated by Sunda Arc subduction zone earthquakes since this area of the coast is protected by the Australian landmass.

\subsection{Deaggregated Tsunami Hazard}

The above results present the variation of offshore tsunami exceedance heights as a function of return period and location along the WA coast. These are based on an aggregate of many different tsunami generated in different parts of the Sunda Arc. These exceedance heights are, therefore, not associated with any particular earthquake or any particular part of the Arc. As discussed above, risk analyses and inundation maps require that inundation modelling be conducted at locations of interest, but these numerical 
a

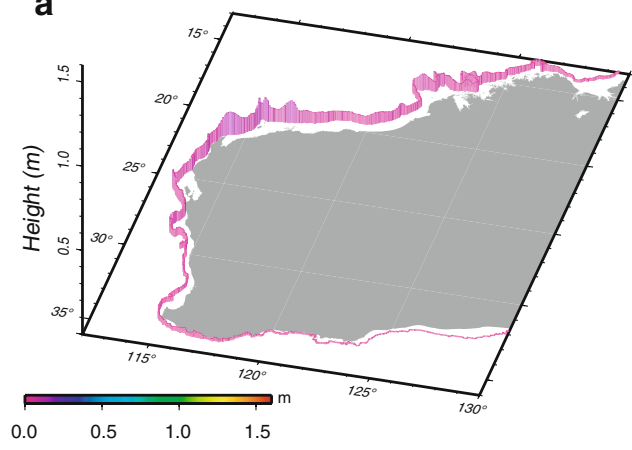

C

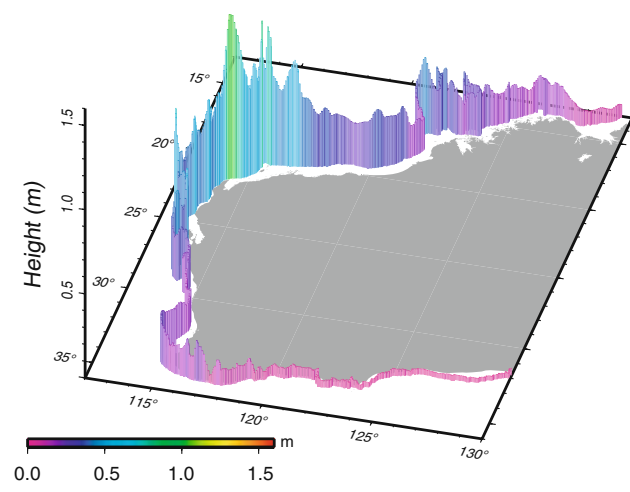

b

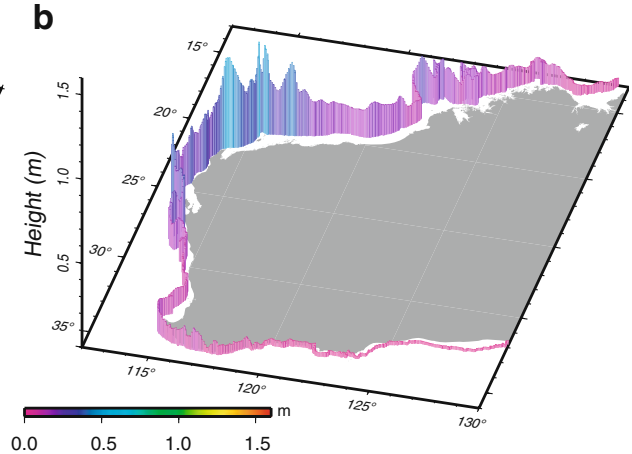

d

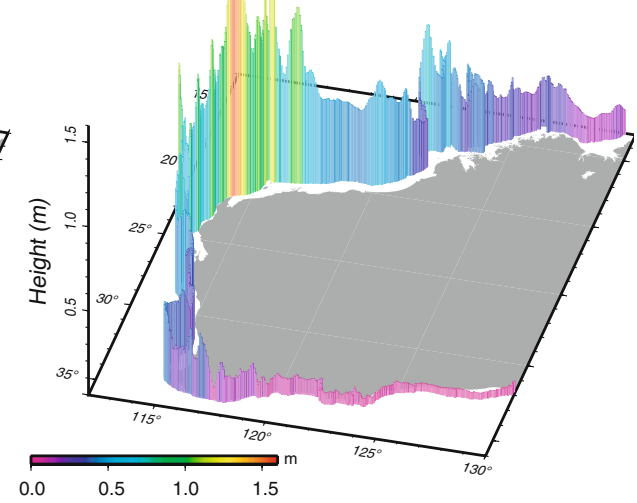

Figure 6

Maximum wave heights along the WA coast (interpolated to the $50 \mathrm{~m}$ depth contour) with mean return period of (a) 100 years, (b) 500 years, (c) 1000 years and (d) 2000 years.

computations can only be realistically performed on a per-event basis. Some objective decision must be made then, about which earthquake or set of earthquakes should be used for inundation modelling at a particular location.

The decision of which scenario(s) to simulate for a particular location of interest is complicated by the fact that tsunami propagation is very sensitive to bathymetry, so that it is difficult to tell which part of a coastline will be most affected by a tsunami excited by a given source. This is illustrated in Figure 7a, where the pattern of energy radiated by the 17 July, 2006 Java earthquake is shown. As has been the case for most historical tsunami in WA, most parts of the coast did not experience a significant tsunami during this event, but the combined influence of deep ocean and near-shore bathymetry resulted in pronounced focussing of tsunami energy at a few very limited stretches of coastline. In this case, such focussing lead to a $9 \mathrm{~m}$ tsunami runup at Steep Point (purple bar in Fig. 1), the highest ever measured in Australia. 

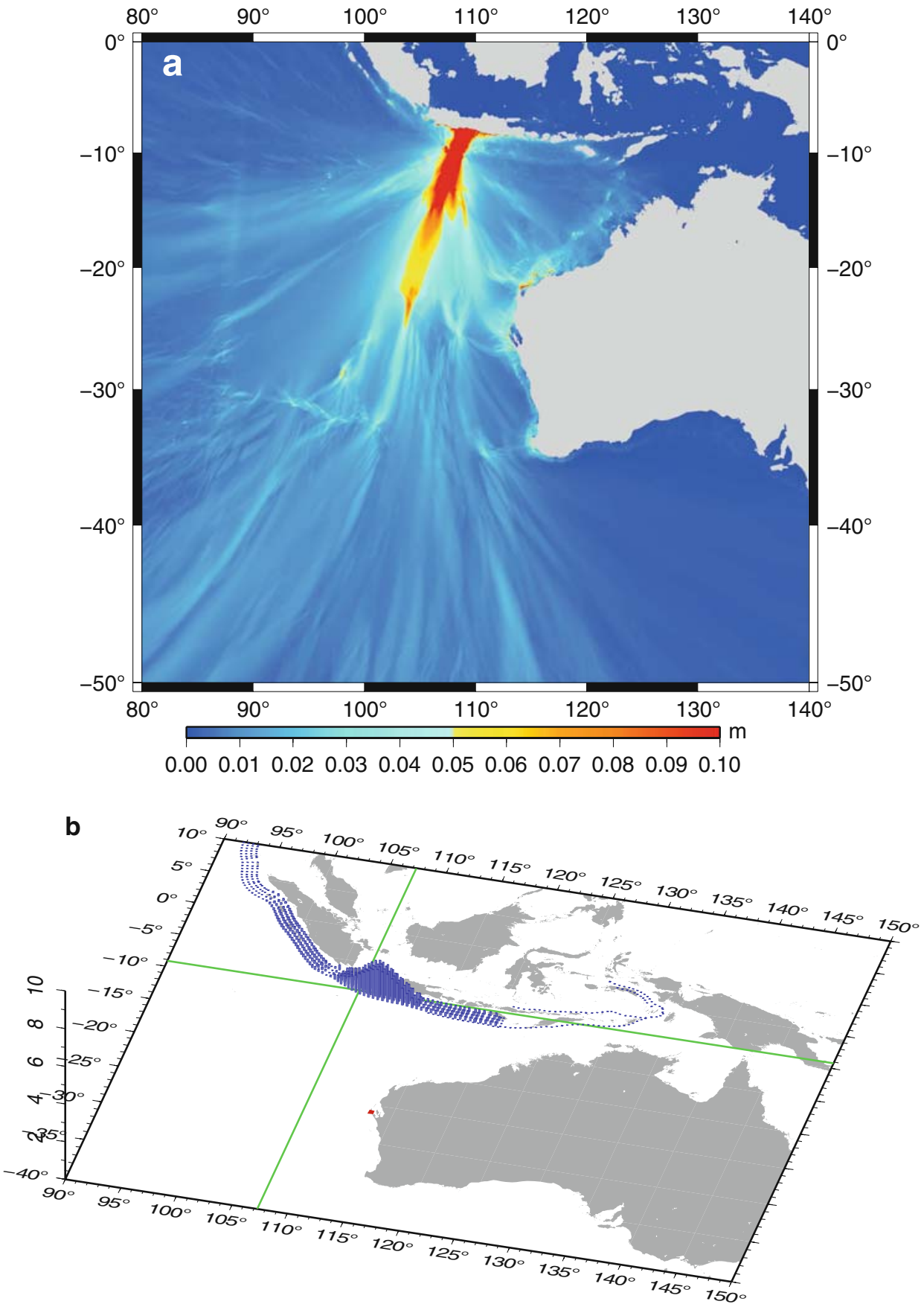
Figure 7

(a) Maximum tsunami amplitude in the Indian Ocean calculated for the 17th July, 2006 Java earthquake, which resulted in a 9-m tsunami runup at Steep Point, WA; (b) Tsunami hazard deaggregation for Steep Point WA, showing the tsunami hazard at Steep Point is dominated by earthquakes near the epicenter of the 2006 Java earthquake (indicated by green crosshairs). The height of the column shows the percentage of the probability that comes from each unit source for the location of the red dot (Steep Point).

Geographic deaggregation of probabilistic hazard is used in PSHA (e.g., HARMSEN and FRANKEL, 2001) for the determination of the location of the most probable source contributing to the hazard at a particular site. This technique is used here to determine the source locations along the Sunda Arc which make the largest contribution to the hazard at a particular site of interest, for a given offshore tsunami exceedance height. Once a particular section of the Sunda Arc has been identified as making the dominant contribution to the hazard at a site of interest, then one or more scenarios appropriate to that section of the arc can be used for inundation modelling. This idea is illustrated in Figure $7 b$, where the deaggregation for Steep Point (red dot in the fig.) is shown for an exceedance height of $0.5 \mathrm{~m}$. The deaggregation shows that the 2006 Java earthquake occurred precisely where we would expect the dominant contribution to tsunami hazard at Steep Point to originate. If we had been concerned about tsunami impacts at this site, even prior to the occurrence of the 2006 event, the deaggregation would have suggested that inundation modelling be performed for a scenario similar to that event. Such modelling should have established that these events can lead to high runup at Steep Point, knowledge which may have been useful had it been available at the time of the tsunami.

Deaggregated tsunami hazard for an exceedance height of $0.5 \mathrm{~m}$ is shown in Figure 8 for Christmas Island and a selection of three sites along the WA coast: Broome, Exmouth, Freemantle. These show that the bulk of the hazard at this wave height for communities in the northern part of WA comes from the eastern Sunda Arc off Sumba (Fig. 8a). For communities further to the south, the most important region becomes first Java (Fig. 8b) and then to some extent Sumatra (Fig. 8c) becomes increasingly important. However, for most locations Java is the single most important section of the Sunda Arc. This is due to both Java being predicted to be quite active and offshore bathymetry which tends to focus the tsunami towards the coast (Fig. 7a). The Java section only becomes roughly as important as the Sumatra section for the WA coast south of Fremantle (Fig. 8c). The hazard faced by Christmas Island, just to the south of Indonesia, is naturally dominated by the subfaults immediately to the north of the island, off Java (Fig. 8d).

\section{Conclusion}

We have completed a probabilistic tsunami hazard assessment for WA for earthquakes generated by subduction zone earthquakes. The results of this assessment 

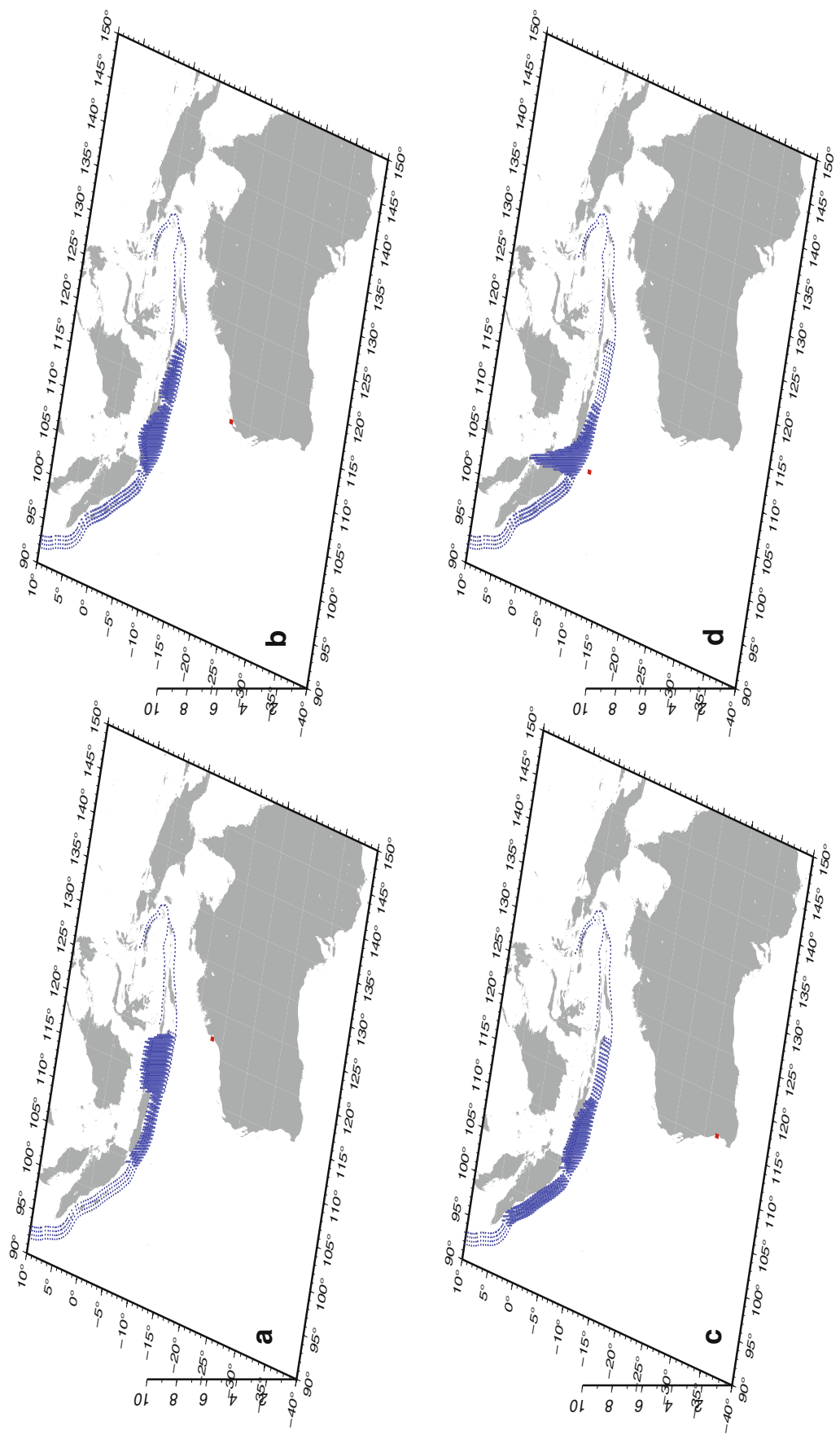


\section{Figure 8}

Tsunami hazard deaggregations calculated for a tsunami exceedence height of $0.5 \mathrm{~m}$, for: (a) Broome; (b) Exmouth; (c) Freemantle, and; (d) Christmas Island. The height of the column shows the percentage of the probability that comes from each unit source for the location of the red dot.

show that the area offshore Exmouth consistently has the highest hazard (at $50 \mathrm{~m}$ water depth) for any location along the WA coast, and that the hazard is moderate to high offshore the region roughly between Shark Bay and Dampier, and is moderate offshore the region between Dampier and Broome. The hazard is much lower further to the south of Shark Bay, and is very low along the south coast of WA. The hazard assessment reported here gives an indication of which areas of the WA coastline are most likely to experience tsunamis, and how likely such events are. The central to southern part of the west coast is most likely to be affected by the Java segment of the Sunda Arc, while the northeastern part of the west coast is mostly affected by the Sumba section of the arc. Bathymetric focussing seems to generate large waves in the Exmouth area.

From the perspective of constraining the hazard, one of the urgent priorities identified by this report is the development of a better understanding of the maximum size of earthquakes which could occur off Java and Sumba. There have been no historical events of magnitude 9.0 in this area, but if they occur they will likely generate tsunami heights on the WA coast considerably larger than what has been experienced historically. However, accurately estimating slip rates and seismic coupling for subduction zones is a very difficult scientific problem and is likely to remain so for some time.

\section{Acknowledgements}

The authors would like to acknowledge the editor, Kenji Satake and the reviewers of this paper, Tom Parson, John Schneider and an anonymous reviewer for their contributions to this manuscript. We would also like to thank the reviewers who also reviewed the original report on which this paper is based, namely Eric Geist, William Power, Clive Collins, Augusto Sanabria and Chris Thomas. Finally we would also like to acknowledge the financial contribution made by the Fire and Emergency Services Authority, Western Australia, who helped to fund this project.

\section{REFERENCES}

Abercrombie, R. E., Аntolik, M., and Екstrom, G. (2003), The June $M_{w} 7.9$ earthquake south of Sumatra: Deformation in the India-Australia Plate, J. Geophys. Res. 108, B1, 2018, doi:10.1029/ 2001JB000674. 
ACHARYYA, S. K. (1998), Break-up of the greater Indo-Australian continent and accretion of blocks framing south and east Asia, J. Geodynamic 26, 149-170.

BEAUREgARD, J. O. (2001), Explosive rhyodacitic volcanism: The evolution and frequency of pre-1883 eruptions at Krakatau volcano, Indonesia, Ph.d. Thesis, University of Rhode Island, $358 \mathrm{pp}$.

Bird, P. (2003). An updated digital model of plate boundaries, Geochem. Geophys. Geosys., 4, 1027, doi:10.1029/2001GC000252.

Bird, P. and Kagan, Y. Y. (2004), Plate-tectonic analysis of shallow seismicity: Apparent boundary width, beta, corner magnitude, coupled lithosphere thickness, and coupling in seven tectonic settings, Bull. Seism. Soc. Am. 94, 2380-2399.

Bland, P. A. and Artemieva, N. A. (2003), Efficient disruption of small asteroids in Earth's atmosphere, Nature 424, 288-290.

Bock, Y., Prawirodirdjo, L., Genrich, J. F., Stevens, C. W., McCaffrey, R., Subarya, C., Puntodewo, S. S. O., and Calais, E. (2003), Crustal motion in Indonesia from Global Positioning System measurements, J. Geophys. Res. 108, 2367.

Burbidge, D. R. and BRAun, J. (1998), Analogue models of obliquely convergent continental plate boundaries, J. Geophys. Res. 103, B7, 15,221-15,237.

Burbidge, D. and Cummins, P. (2007), Assessing the hazard to western Australia from tsunami generated by earthquakes along the Sunda Arc, Natural Hazards 43(3), 319-331.

Chamot-Rooke, N., Jestin, F., De Voogd, B. and Phedre Working Group (1993), Intraplate shortening in the central Indian Ocean determined from a 2100-km-long north-south deep seismic reflection profile, Geology 21, 1043-1046.

Chesley, S. R. and WARD, S. N. (2006), A Quantitative assessment of the human and economic hazard from Impact-generated Tsunami, Natural Hazards 38, 355-374.

Cornell, C.A. (1968), Engineering seismic risk analysis, Bull. Seismol. Soc. Am. 58, 1583-1606.

Cruciani, C., Carminati, E., and Doglioni, C. (2005), Slab dip vs. lithosphere age: No direct function, Earth Planet. Sci. Lett. 238, 298-310.

Cummins, P. R. (2007), The potential for giant tsunamigenic earthquakes in the northern Bay of Bengal, Nature. 229, 75-78.

Dominey-Howes, D., Cummins, P., and Burbidge, D. (2006), Historic records of teletsunami in the Indian Ocean and insights from numerical modelling, Natural Hazards Doi: 10.1007/s11069-006-9042-9.

GeIst, E. L. (2002), Complex earthquake rupture and local tsunamis, J. Geophys. Res. 107, 5, $2-1$.

Geist, E. L. and Parsons, T. (2006), Probabilistic analysis of tsunami hazards, Natural Hazards 37, $277-314$.

Gusiakov, V. K. (2005), Integrated tsunami database for the world ocean, version 5.15, Tsunami Laboratory, ICMMG SD RAS, Novosibirsk, Russia.

Hyndman, R. D. and WAng, K. (1993), Thermal constraints on the zone of major thrust earthquake failure: The Cascadia subduction zone, J. Geophys. Res. 98, 2039-2060.

Harmsen, S. C. and Frankel, A. D. (2001), Geographic deaggregation of seismic hazard in the Untied States, Bull. Seismol. Soc. Am. 91, 13-26.

Horrillo, J., Kowalik, Z. and Shigihara, Y. (2006), Wave dispersion study in the Indian Ocean-Tsunami of December 26, 2004, Marine Geodesy 29, 149-166.

JENkins, C. J. and KeENE, J. B. (1992), Submarine slope failures of the southeast Australian continental slope: A thinly sedimented margin, Deep-Sea Research 39, 121-136.

KaGan, Y. Y. (2002), Seismic moment distribution revisited: II. Moment conservation principle, Geophys. J. Int. $149,731-754$.

Kopp, H. (2002), BSR occurrence along the Sunda margin: Evidence from seismic data, Earth Planet. Sci. Lett. $197,225-235$.

Korycansky, D. G. and Lynett, P. J. (2005), Offshore breaking of impact tsunami: The Van Dorn effect revisited, Geophys. Res. Lett. 32, 1-4.

Kramer, S. L., Geotechnical Earthquake Engineering (Prentice Hall, New Jersey, 1996).

Laske, G. and Masters, G. (1997), A Global Digital Map of Sediment Thickness, EOS Trans. AGU 78, F483.

Liu, Y., SAntos, A., WAng, S. M., Shi, Y., Liu, H., and Yuen, D. A. (2007), Tsunami hazards along Chinese coast from potential earthquakes in South China Sea, Phys. Earth Planet. Int. 163, 233-244. 
McCAffrey, R. (1988), Active tectonics of the eastern Sunda and Banda Arcs, J. Geophys. Res. 93, B12, $15,163-15,182$.

McGuiRe, R. K. (1976), FORTRAN computer program for seismic risk analysis, U. S. Geolog. Survey Open File Report 76-67, pp. 90.

Melosh, H. J. (2003), Impact-generated tsunamis: An over-rated hazard. Lunar Planet. Sci. Conf. 34, Abstract 2013.

Natawidjaja, D. H., Sieh, K., Chlieh, M., Galetzka, J., Suwargadi, B. W., Cheng, H., Edwards, R. L., Avouac, J.-P., and WARD, S. N. (2006), Source parameters of the great Sumatran megathrust earthquakes of 1797 and 1833 inferred from coral microatolls, J. Geophys. Res. 111, doi:10.1029/2005JB004025.

Newcomb, K. R. and McCann, W. R. (1987), Seismic history and seismotectonics of the Sunda Arc, J. Geophys. Res. 92, 421-439.

Nishenko, S. P. (1991), Circum-Pacific seismic potential: 1989-1999, Pure Appl. Geophys. 135, 169-259.

NotT, J. and BRyAnt, E. (2003), Extreme marine inundations (tsunamis?) of coastal western Australia, J. Geology 111, 691-706.

Okal, E. A. and Reymond, D. (2003), The mechanism of great Banda Sea earthquake of 1 February 1938: applying the method of preliminary determination of focal mechanism to a historical event, Earth and Planet. Sci. Lett. 216, 1-15.

Oleskevich, D. A., Hyndman, R. D., and WAng, K. (1999), The up-dip and down-dip limits to great subduction zone earthquakes: Thermal and structural models of Cascadia, South Alaska, SW Japan, and Chile, J. Geophys. Res 104, 14,965-14,991.

Pacheco, J. F. and Sykes, L. R. (1992), Seismic moment catalog of large, shallow earthquakes, 1900-1989, Bull. Seismol. Soc. Am. 82, 1306-1349.

Pacheco, J. F., Sykes, L. R., and Scholz, C. H. (1993), Nature of seismic coupling along simple plate boundaries of the subduction type, J. Geophys. Res. 98, 14133-14159.

Purcaru, G. and Berckhemer, H. (1978), A magnitude scale for very large earthquakes, Tectonophys. 49, 189198.

RikitaKe, T. and AidA, I. (1988), Tsunami hazard probability in Japan, Bull. Seismol. Soc. Amer. 78, 12681278.

RuFF, L. (1989), Do trench sediments affect great earthquake occurrence in subduction zones? Pure Appl. Geophys. 129, 263-282.

Ruff, L. and Kanamori, H. (1980), Seismicity and the subduction process, Phys. Earth Planet. Int. 23, $240-252$.

Rynn, J. and Davidson, J. (1999), Contemporary assessment of tsunami risk and implications for early warning for Australia and its Island Territories, Sci. Tsunami Hazard 17(2), 107-125.

Scholtz, C. H., The Mechanics of Earthquakes and Faulting, Second Edition (Cambridge Univeristy Press, UK, 2002).

SPENCE, W. (1986), The 1977 Sumba earthquake series: Evidence for slab pull force acting at a subduction zone, J. Geophys. Res. 91, 7225-7240.

Stein, S. and Okal, E. (2007), Ultralong Period Seismic Study of the December 2004 Indian Ocean Earthquake and Implications for Regional Tectonics and the Subduction Process, Bull. Seismol. Soc. Am. 97, S279-S295.

Thio, H. K., Somerville, P., and Inchinose, G. (2008), Probabilistic analysis of strong ground motion and tsunami hazards in southeast Asia, J. Earthquakes and Tsunami, 1, 119-137.

Tsutsumi, A., Shimamoto, T., Kawamoto, E., and Logan, J. M. (2000), Nearshore flow velocity of Southwest Hokkaido earthquake tsunami, J. Waterway, Port, Coastal, and Ocean Engineering, 126, 136-143.

WAng, R., Martin, F. L., and Roth, F. (2006), Computation of deformation induced by earthquakes in a multi-layered crust - FORTRAN programs, EDGRN EDCMP, Comp. and Geosc. 29, 195-207 (inc. erratum).

Ward, S. N. and Asphaug, E. (2000), Asteroid impact tsunami: A probabilistic hazard assessment, Icarus 145, 64-78.

WARD, S. N. and DAy, S. (2001), Cumbre Vieja volcano - potential collapse and tsunami at La Palma, Canary Islands, Geophys. Res. Lett. 28, 3397-3400.

Wells, R. E., Blakely, R. J., Sugiyama, Y., Scholl, D. W., and Dinterman, P. A. (2003), Basin-centered asperities in great subduction zone earthquakes: A link between slip, subsidence and subduction erosion? J. Geophys. Res. 108, 2507, doi:10.1029/2002JB002072. 
Zachariasen, M., Sieh, K., Taylor, F. W., Edwards, R. L., and Hantoro, W. S. (1999), Submergence and uplift associated with the giant 1833 Sumatran subduction earthquake: Evidence from coral microatolls, J. Geophys. Res. 104, 895-919.

(Received April 6, 2008, accepted July 18, 2008)

Published Online First: December 19, 2008

To access this journal online:

www.birkhauser.ch/pageoph 